\title{
FIBROMATOSE GENGIVAL HEREDITÁRIA - RELATO DE DOIS CASOS
}

Fábio Alves IZIDORO, Ana Claudia Santos de Azevedo IZIDORO, Andressa Marafon SEMPREBOM, Roberta Targa STRAMANDINOLI, Luciana Damasceno Ferreira KANUNFRE

A fibromatose gengival hereditária $(F G H)$ é uma condição bucal rara (1:750.000), de herança autossômica dominante ou recessiva, caracterizada clinicamente pelo crescimento gengival contínuo e progressivo, indolor, não hemorrágico, que pode recobrir total ou parcialmente as coroas dos dentes. Sem predileção por sexo, pode variar a sua expressão de leve a grave em indivíduos de uma mesma família. O aumento gengival é proveniente de hiperplasia não inflamatória dos componentes do tecido conjuntivo, os eventos moleculares que levam a esse aumento ainda não são totalmente conhecidos. De acordo com a literatura consultada, a presença do dente é necessária para que a condição ocorra. Este painel descreve dois casos afetando irmãos, um menino de 6 anos e uma menina de 15 anos, da cidade de Curitiba, Paraná. Ambos apresentavam FGH generalizada, com dois terços das coroas recobertos por gengiva fibrótica. A mãe relatou ter sido portadora da forma grave da doença. O tratamento instituído foi uma associação de gengivectomia e gengivoplastia por quadrantes, possibilitando a realização dos procedimentos necessários. Amostras foram enviadas para exame anatomopatológico, confirmando o diagnóstico clínico de FGH. A família recebeu orientações sobre o caráter familial da doença e vem sendo acompanhada periodicamente, devido à tendência de recidivas. 